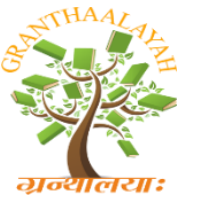

INTERNATIONAL JOURNAL OF RESEARCH -

RAST - 17

\title{
OPTIMAL SOLUTION FOR THE DISTRIBUTION OF BY-PRODUCTS IN DISPOSAL UNIT
}

\author{
Jyothi.P ${ }^{* 1}$, Vatsala G A ${ }^{2}$, RadhaGupta ${ }^{3}$ \\ ${ }^{* 1}$ Research Scholar, Jain University, Bangalore, Karnataka, India \\ ${ }^{2}$ Associate Professor, Department of Mathematics, DSATM, Karnataka, Bangalore, India \\ ${ }^{3}$ Professor, Department of Mathematics, Dayananda Sagar University, Bangalore, Karnataka, \\ India
}

DOI: https://doi.org/10.5281/zenodo.803426

\begin{abstract}
In present scenario, Waste disposal unit is one of the emerging industries. The process of collection of wastes, segregation of wastes, recycling the wastes and manufacturing by-products and selling the by-products are the major works are undertaken into consideration. Any business expectation is to get the profit. Our study is to formulate goal programming model which helps in maximizing the profit by identifying the deviation of goals in the disposal unit. Goal Programming technique is one of the optimization techniques. Manager of the disposal unit can takes the better decision using the deviation of goals. Pre emptive Goals of the study are (i) minimizing the expenditure of the unit and recycling cost of the wastes ii) boosting the net profit of the unit iii) Maintaining the supply of by-products to each location within the maximum demand iv) Fulfilling demand of by- products in different locations v) Maintaining the minimum supply of recycled by-products to 5 different locations must be at least one.
\end{abstract}

Keywords: Goal Programming; Deviation; Optimization; Underachievement; Overachievement.

Cite This Article: Jyothi.P, Vatsala G A, and RadhaGupta. (2017). "OPTIMAL SOLUTION FOR THE DISTRIBUTION OF BY-PRODUCTS IN DISPOSAL UNIT.” International Journal of Research - Granthaalayah, 5(4) RAST, 59-63. https://doi.org/10.5281/zenodo.803426.

\section{Introduction}

In present scenario wastes are not treated as useless material. Recycling process of converting waste into new and useful by-products and this major work is undertaken by disposal waste management centers. Wastes such as papers, cardboard, metal, plastic, rubber items, tires, textiles, glass, electronic items, old vehicles, wood, chemicals from the factory etc. can be recycled into useful by-products. Wastes are treated as assets as the same can be transformed into by-products and results in profit. Food wastes \& Garden wastes are also considered assets as these too can be recycled into composites or bio-gas which can be used as fuel. 
Disposal of waste in cities has become a challenging task due to many reasons like over population and urban areas , the Government introduced Waste Management Centers all over the country. The Disposal Units are the part of Waste Management Centers. Disposal Units/Recycled units focuses on tasks like collect wastes from nearby areas, making the segregations of collected wastes, cleaning and recycling, producing \& selling by-products to various locations where the demand is high. The Disposal Units/recycling units helps the public by reducing the pollution \& keeping the environment clean and neat, increasing the growth of economy as well as providing more job opportunities for the people of the country. As other industries focuses on profit, Disposal Units also make profit by distributing \& selling the recycled products to different locations by distributing properly where the demand is high. Role, responsibility as well as functions of each Waste Disposal Units differ according to its capacity and capability. For example, some would only collect and dispose of the waste. Larger units would collect, segregate, clean, and recycle the waste. Bigger industries would sell the recycled products to various vendors at different locations and make big profit.

Some of the by-products, the Waste Disposal Units interested in manufacturing and selling either locally or to different locations are recycled papers, cardboards, tetra packs, carry bags, plastic toys, buckets, mugs, ropes, wires, kitchenware items, glass items, recycled plywood, press wood, mica. These by products are high in demand because of its low cost. Wet wastes like kitchen wastes, food, fruits, vegetables, leaves etc. are converted into bio-gas, organic fertilizers, composites which are also in high demand in the market.

Our study on Formulation of Goal Programming Model is to help the Waste Disposal Units to plan the distribution and selling off by-products thereby enhancing the profit.

The unit recycles the waste papers into useful papers, cardboards etc. \& sells that to different 5 locations. Toys, buckets, mugs, plastic parts of car and many more items of plastics can be manufactured by recycling Similarly, Recycled glass items, Recycled wood items and recycled tetra packs are also high in demand. Benefits of recycling of wet wastes are generating bio-gas, organic fertilizer, wormy compost which is very much demands in market. These recycled products are purchased by vendors of different companies. Selling the same by-products to 5 different locations with profit is the main intention of this study. Different locations may have different demands on these by-products. The study helps the company for planning of selling off by-products. The goal programming model helps the unit in enhancing the profit of the sales of by-products and by proper distributing of by-products.

\section{Assumptions}

1) As per customer needs demand varies from location to location

2) Both supplier of products and buyer of product borne equally

3) Difference between total sales and production cost is the gross profit.

4) The net profit (monthly) must be at least $35 \%$ of the allocated budget.

5) The by-products of the company sent to all 5 locations must not be nil 


\section{Model Development}

(1) Demand of $i^{\text {th }}$ by-product from location

$$
\begin{gathered}
z_{i j}=D_{i j}---(1) \quad i=1,2 \ldots . .10, \quad j=1,2,3,4,5, \\
z_{i j}+d_{k}^{-}-d_{k}^{+}=D_{i j}---(2) \quad k=1,2,3 \ldots .50
\end{gathered}
$$

2)The net profit of the disposal/recycled unit need to be at least $35 \%$ of the budget allocation

$\sum_{i=1}^{10} \eta_{i} z_{i 1}-\chi_{k}+\sum_{i=1}^{10} \eta_{i} z_{i 2}-\chi_{L}+\sum_{i=1}^{107} \eta_{i} z_{i 3}-\chi_{M}+\sum_{i=1}^{10} \eta_{i} z_{i 4}-\chi_{N}+\sum_{i=1}^{10} \eta_{i} z_{i 5}-\chi_{O} \geq 0.35 B$

The first part of the above inequality is the net Profit from10 types of by-products which manufactured in the unit. The gross profit \& delivery cost difference will results in net profit in each location. $\chi_{k} \chi_{L} \chi_{M} \chi_{N} \chi_{O}$ are the delivery costs of by products to 5 different locations.

$$
\begin{aligned}
& \sum_{i=1}^{10} \eta_{i} z_{i 1}-\chi_{k}+\sum_{i=1}^{10} \eta_{i} z_{i 2}-\chi_{L}+\sum_{i=1}^{10} \eta_{i} z_{i 3}-\chi_{M}+\sum_{i=1}^{10} \eta_{i} z_{i 4}-\chi_{N}+\sum_{i=1}^{10} \eta_{i} z_{i 5}-\chi_{O}+d_{51}^{-}-d_{51}^{+}=0.35 B----(4) \\
& \sum_{i=1}^{10} \eta_{i} z_{i 1}+\sum_{i=1}^{10} \eta_{i} z_{i 2}+\sum_{i=1}^{10} \eta_{i} z_{i 3}+\sum_{i=1}^{10} \eta_{i} z_{i 4}+\sum_{i=1}^{10} \eta_{i} z_{i 5}+d_{51}^{-}-d_{51}^{+}=0.35 B+\chi_{k}+\chi_{L}+\chi_{M}+\chi_{N}+\chi_{O}----(5)
\end{aligned}
$$

3) The cost spent for the collection of wastes, segregation of wastes, transportation of the wastes to the unit, and salary for the employees\& recycling in the disposal/recycled unit should not exceed the allocated budget

$$
\begin{aligned}
& \sum_{i=1}^{10} E_{i} z_{i j}+\sum_{i=1}^{10} \sum_{j=1}^{5} R_{i} z_{i j} \leq B------(6) \\
& \sum_{i=1}^{10} E_{i} z_{i}+\sum_{i=1}^{10} \sum_{j=1}^{5} R_{i} z_{i j}+d_{52}^{-}-d_{52}^{+}=B------(7)
\end{aligned}
$$

4)The supply of by-products to each location monthly must be within the maximum demands

$$
\begin{aligned}
& \sum_{j=1}^{5} z_{i j} \leq S_{i}^{u} i=1,2, \ldots .10----(8) \\
& \sum_{j=1}^{5} z_{i j}+d_{53}^{-}-d_{53}^{+}=S_{i}^{u}----(9) \quad i=1,2, \ldots .10
\end{aligned}
$$

5)Supply of each by-products must be at least 1

$$
\begin{aligned}
& z_{i j} \geq 1, i=1,2,3 \ldots 10, j=1,2 \ldots 5 \\
& z_{i j}+d_{54}^{-}-d_{54}^{+}=1----(10)
\end{aligned}
$$


The Priority level of the GP Model as follows

$\mathrm{P}_{1}$ : Expenditure and recycling cost does not exceed the allocated monthly budget

$\mathrm{P}_{2}$ : The net profit of the disposal recycling unit must be at least 35\% of the total budget

$\mathrm{P}_{3}$ : Supply of by-products to each location (monthly)must be within the maximum demand

$\mathrm{P}_{4}$ : Demand of products is to be fulfilled

$\mathrm{P}_{5}$ : Maximum supply of recycled by-products to 5 different locations must be at least one

\section{Achievement Function}

$$
\text { Minimize }=P_{1} d_{52}^{+}+P_{2} d_{51}^{+}+P_{3} d_{53}^{+}+P_{4} d_{k}^{-}+P_{5} d_{54}^{-}
$$

\section{Results and Conclusion}

The goal programming model is developed for finding the optimal solution to the distribution of by-products which manufactured in Garbage disposal unit/recycled unit to different locations. The waste products collected by disposal unit are plastic, Aluminum metal, metals, Papers, glass \& wood. Recycled by-products are of many varieties. We have considered 10 types of byproducts and distribution to 5 locations in our study.

Developed Goal Programming Model is useful tool for the profit of Garbage disposal \&recycled unit. This determines the distribution of by-products to different locations to satisfy the growing demands of their markets. To meet all the demands of locations proper planning is required. This will ensure supply of by-products to different locations by ensuring profit. Planning of distribution will ensure the profit of the unit. This formulated model can be further tested with the statistical data.

In this paper we tried to formulate a mathematical model by considering only 10 types of byproducts and 5 different locations. Distribution of these varieties of by-products may be increased to more number locations \& optimal solution may be achieved from this model. Solution may be achieved on the basis of data collected. The software's like MAT LAB, Tora, excel solver helps in achieving the desired results.

\section{Acknowledgement}

We would thank our colleagues, friends, municipality members \& others those who gave valuable information related to garbage disposal and the process of recycling.

\section{References}

[1] D.K.Sharma \& A.Gaur \& D. Ghosh. "GOAL PROGRAMMING MODEL FOR AGRICULTURAL LAND ALLOCATION PROBLEMS”, International Journal of Modelling and Simulation, Vol .28, Issue1, 2008

[2] Nabendu Sen and Manish, [2012] "AN OPTIMAL MODEL USING GOAL PROGRAMMING FOR RUBBER WOOD DOOR MANUFACTURING FACTORY IN TRIPURA”, Mathematical Theory and Modelling, Vol. 2, No.8 
[3] Jayashree D.N \& Radha Gupta [2016] "OPTIMUM ALLOCATION OF RESOURCES IN UNIVERSITY MANAGEMENT THROUGH GOAL PROGRAMMING”, Global Journal of Pure and applied Mathematics, ISSN 0973-1768 Vol .12, no.4 Research India Publication

[4] Ekezie Dan Dan\&OnuohaDesmond.O [2013] "GOAL PROGRAMMING: AN APPLICATION TO BUDGETARY ALLOCATION OF AN INSTITUTION OF HIGHER LEARNING”, Research Journal in Engineering and Applied Sciences 2(2)95-105

[5] Wiwik Anggraeni \& Retno Aulia Vinarti[2015] "PRODUCTION PLANNING OPTIMIZATION USING GOAL PROGRAMMING METHOD IN HABIBAHBUSANA", Journal of Advanced Management Science, Vol 3 no.4

[6] Nasruddin Hassan \& [2012] "A GOAL PROGRAMMING APPROACH FOR FOOD PRODUCT DISTRIBUTION OF SMALL AND MEDIUM ENTERPRISES", Advances in Environmental Biology, ISSN 1995-0756, 6:2:510-13

[7] Narendra KumarG.,Chandrika Swamyand, K.N.Nagadarshini [2014] "EFFICIENT GARBAGE DISPOSAL MANAGEMENT IN METROPOLITAN CITIES USING VANETS", Journal of Clean Energy Technologies, Vol.2, No.3:136

\footnotetext{
*Corresponding author.
}

E-mail address: jyothi_balu_95@yahoo.co.in 